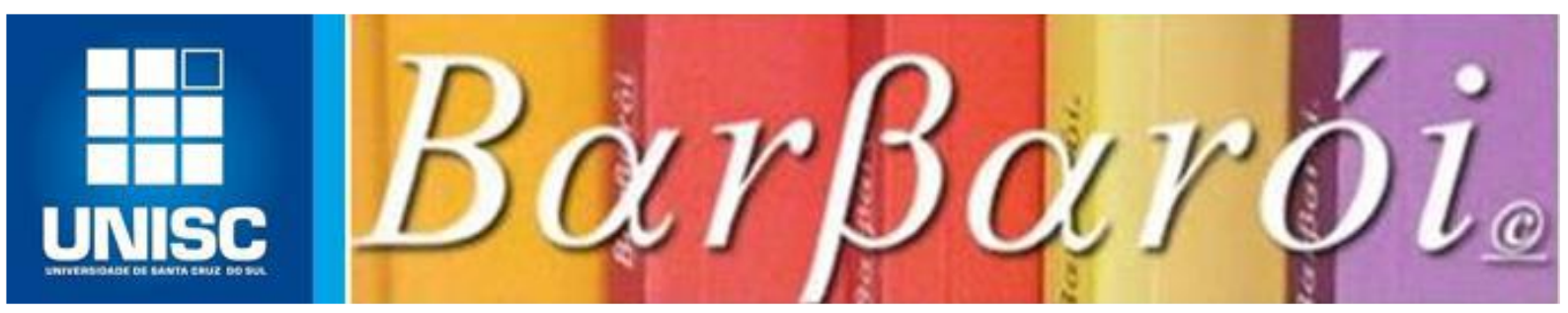

\title{
O ATO DE PRESENTEAR COMO PROCESSO DE SACRALIZAÇÃO: O ESCAPULÁRIO COMO SÍMBOLO DE AMOR E PROTEÇÃO
}

\author{
DOI: http://dx.doi.org/10.17058/barbaroi.v0i58.14455 \\ $*$ \\ Larissa Ruiz Golemba de Britto \\ Universidade Estadual de Maringá - UEM - Brasil \\ Olga Maria Coutinho Pépece \\ Universidade Estadual de Maringá - UEM - Brasil \\ Ana Paula Celso de Miranda \\ Universidade Federal de Pernambuco - UFPE - Brasil \\ Elisabete Camilo \\ Universidade Estadual de Maringá - UEM - Brasil
}

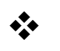

\section{Resumo}

Com objetivo de compreender como acontece a sacralização do objeto de consumo escapulário para católicos realizou-se uma investigação qualitativa. Foram realizadas entrevistas com católicos que usam escapulário regularmente. Os discursos coletados passaram pela análise de conteúdo que revelou como resultado de pesquisa que o local do "sagrado" em relação ao escapulário, está vinculado à sua capacidade de proteger seu usuário. Ainda essa capacidade de proteção não está vinculada apenas ao objeto em si, mas no fato deste ter sido recebido como presente de uma pessoa amada. O que sacraliza então não é apenas a religião, mas a relação de afeto entre quem recebeu o escapulário de presente e a pessoa que o presenteou.

Palavras-chave: Sacralização; Ato de presentear; Objetos amados.

\section{Introdução}

Estudos sobre consumo tais como o de Douglas e Isherwood (2006) afirmam que o consumidor procura adquirir determinado bem porque ao se apropriar dele, pode tornar visíveis aspectos particulares seus, como para dizer algo sobre si mesmo, sua família, sua localidade. A preocupação central está no julgamento do outro e em determinados processos de classificação no convívio social. O presente estudo visa entender o processo de sacralização do objeto Escapulário para católicos que usam este item. O escapulário é um objeto símbolo da religião cristã católica, que 
consiste nas imagens dos Sagrados Corações de Jesus Cristo e de Nossa Senhora, sendo que uma imagem fica sobre o peito e a outra sobre as costas, como sinal de proteção para o que se pode ver e daquilo que não se pode ver. O escapulário é feito tradicionalmente de pano, mas atualmente é encontrado em diversos materiais: escapulários de ouro, de prata, bronze ou mesmo de madeira. Para os fiéis este não deve ser comprado, mas presenteado para que a sua função de proteção se concretize. A palavra escapulário surgiu a partir do latim scapula, que quer dizer "armadura" ou "proteção", referente também à região do ombro e da escápula, osso localizado na região dos ombros e acima do tórax humano onde o escapulário irá repousar, pois o escapulário fica sobre a escápula.

O uso do escapulário, para os católicos, simboliza um ato de devoção à Virgem Maria, mãe de Jesus Cristo. (Pe. LUIZINHO, 2020). Segundo estudo dos autores Park e Baker (2007), o consumo de produtos é determinante para marcar a identidade do consumidor e uma das formas desta marcação de identidade ocorre dentro da religião, pois é por meio desses símbolos do sagrado que há a exteriorização e a materialização da fé deste indivíduo. Por outro lado, Belk, Wallendorf e Sherry (1989), pontuam que ocorreu uma gradual secularização da religião e uma gradual sacralização do secular. Assim, o objetivo deste artigo é entender as trajetórias significativas de artefatos com a finalidade de contribuir com o entendimento das correntes de significação, na construção da voz do consumidor e na diagnose da circulação de objetos enquanto produtores de sentido. O objetivo geral deste estudo é contribuir com a compreensão do processo de sacralização do objeto de consumo escapulário para os católicos.

O entendimento dos modos de consumo é uma grande ferramenta para a compreensão da sociedade, pois as pessoas expressam seus valores e suas crenças no consumo e, por meio deste também materializam sua cultura (DOUGLAS; ISHERWOOD, 2006; MILLER, 2007). Neste contexto, entendem-se os artigos religiosos como manifestações típicas de crenças que são expressas por meio da cultura material dos objetos (RINALLO; SCOTT; MACLARAN, 2012). Esses objetos fazem parte do mercado de artigos religiosos que vem crescendo a cada ano. Em 2014, por exemplo, o mercado de artigos católicos movimentou oito bilhões de reais no Brasil (OLIVEIRA, 2015).

\section{Referencial teórico}

Belk (1988) desenvolveu teoria sobre a relação e apropriação do conceito do eu-estendido (extended self) em que o significado que o indivíduo atribui à posse reflete a sua própria identidade que é projetada no objeto. Ahuvia (2005) contribui com os achados de Belk atribuindo aos bens mais do que a ideia de posse, onde uns são mais importantes que outros porque alguns objetos são tratados 
de forma especial e amados pelo possuidor. Dentre os bens considerados muito importantes encontram-se aqueles ligados à religião. O consumo religioso traz em sua essência uma questão de espiritualidade do indivíduo, ou seja, a pessoa opta por consumir alguns objetos ou atividades religiosas que além de reforçar suas crenças, valores, e significados, ajudam a demonstrar a outras pessoas o comprometimento com a sua religiosidade (COŞGEL; MINKLER, 2004), assim como, a sua relação de pertencimento social (TAJFEL, 1979). Araújo, Vieira e Turano (2013), ratificam essa posição no caso do catolicismo ao afirmarem que a religião pode influenciar ativamente o consumidor durante o processo de aquisição de determinado bem ou serviço. Para Scaraboto e Figueiredo (2015) a religião enquanto experiência estabelece, muitas vezes, o sagrado inerente ao objeto. Os autores revelaram em seu estudo sobre a circulação de pequenas capelas da igreja católica, que há mecanismos responsáveis por promoverem a ligação entre os indivíduos e os objetos que ocorrem por meio de rituais e peregrinações, situações em que os objetos adquirem uma aura sagrada (SCARABOTO; FIGUEIREDO, 2015).

As religiões podem ser percebidas como um resultado de sentimentos compartilhados responsáveis por introduzirem um sistema de crenças e de práticas nas quais o indivíduo pode se sentir completo (ARAÚJO; VIEIRA; TURANO, 2013). Quanto aos objetos de devoção da igreja católica convém salientar que eles são e podem ser vários, além daqueles que hoje conhecemos e sabemos existir. No entanto, existem alguns que são de uso mais geral dos fiéis da Igreja Católica, e muito comuns na religiosidade popular brasileira, entre eles está o escapulário (DIAS; DE SOUZA; DA SILVA, 2014). Nesse sentido, Belk (2013) evidencia que na sociedade contemporânea há o divórcio entre a espiritualidade e a religião, o que pode ser atribuído à secularização da sociedade na qual indivíduos combinam diferentes fontes (filmes, literatura, música, entre outros) para personalizar suas crenças e práticas espirituais. A respeito da secularização, responsável pelo afastamento do indivíduo da religião formal, Belk Wallendorf e Sherry (1989), em seu estudo, buscaram compreender como as discussões sobre a secularização da sociedade ocidental expõem essas relações de consumo e, consequentemente, os significados sagrados atrelados. Os autores demonstraram que, com a polarização da religiosidade vinda do período moderno, houve a substituição da secularização por aspectos relacionados ao sagrado e ao profano, que formou a concepção da ideia secular no consumo. Da análise do sagrado e profano abordada por Belk, Wallendorf e Sherry (1989), os itens considerados sagrados são representados por experiências transcendentes, o que usualmente ocorre com determinados objetos religiosos e pontuam a existência de seis formas já identificadas de sacralização dos bens na cultura de consumo sendo elas: por rituais, por quintessência, pelo ato de presentear, por coleções, por heranças e por sanção externa. 
Nesse sentido, o consumo, em especial o consumo de objetos se transformou num mecanismo de experimentação do sagrado, explorado por meio do ritual do ato de presentear no qual é possível descrever as propriedades manifestas inerentes a esse fenômeno (BELK, 2013). Mauss (2003), em seus estudos antropológicos já afirmava que na troca de presentes há caráter essencialmente simbólico, pois, a constituição do ato compreende um ritual de doação, bem como de aceitação do presente ofertado, caracterizando-o como um ato simbólico. Oliveira e Viera (2010) destacam, nesse sentido, que o caráter simbólico prevalece também no contexto situacional, pois os bens são utilizados como transmissores dos significados construídos pelos indivíduos, dependendo do contexto em que estão inseridos. Durante o ato de presentear as mensagens são transferidas, normalmente, por meio das diversas ocasiões em que o indivíduo perpassa, nas quais o presente adquire funções determinantes nas relações (BRITTO; 2019). Os presentes, assim, são escolhidos de forma que possam carregar e transmitir um significado não só dos indivíduos, mas também das mensagens e do contexto em que esses são doados, de modo a possibilitar que os indivíduos reconheçam a sua simbologia (BRITTO, 2019; PÉPECE, 2000).

As discussões apresentadas por Belk, Wallendorf e Sherry (1989) sobre a secularização na sociedade ocidental podem ser compreendidas conforme as suas bases de visão antropocêntrica, onde o homem é o centro da vida ao qual propõe que o consumo é uma forma de experienciar significados sagrados (OLIVEIRA; VIERA, 2010). Essa relação corrobora os achados de Huss (2014), que explica haver na vida do indivíduo elementos com muita relação com o consumo, elementos esses que o possibilitam vivenciar o aspecto transcendente das emoções. Portanto, a sacralidade atual desafia a concepção de magia, bem como a de religião, e ao mesmo tempo não a transforma em secular, mas oferece novas adaptações e formas de experienciá-la. Em suma, no que concerne ao processo de sacralização no ato de presentear, evidenciou-se, dentre os diferentes estudos elencados, que independente da cultura em que o ato de presentear é descrito, há a revalorização das emoções, sendo o presente, quando sacralizado, uma forma de o indivíduo se reencantar ou reencontrar o seu transcendente. O presente, neste contexto, é operante no mundo sacralizado pelo indivíduo demonstrando que cabe tão somente a ele a sua transcendência, que é experienciada por meio do consumo.

Sobretudo, Meurer (2011), diz que o homem, ao longo da história da humanidade foi capaz de atribuir valor simbólico ao adorno, principalmente o significado mágico, sendo, portanto, uma espécie de comunicação. Em suma, diferentes significados atrelados aos objetos considerados capazes de conferir proteção contra a ira e o mau olhado, além de serem utilizados a fim de preservarem a memória, também servem para sinalizar o pertencimento a determinado 
grupo, ou seja, é uma comunicação dupla com o campo espiritual e com o campo terreno. Esta prática de utilização de objetos de uso pessoal detentores de alguma simbologia é histórica e nunca deixou de ser praticada.

\section{Percurso Metodológico}

Por meio de uma pesquisa qualitativa foram realizadas 15 entrevistas presenciais semiestruturadas com católicos usuários de escapulários moradores da cidade de Maringá no sul do Brasil onde 64,75\% da população é católica (CENSO, 2010). As entrevistas duraram, em média, 30 minutos e foram realizadas entre os meses de outubro e novembro de 2016. As mesmas foram gravadas, transcritas e analisadas por meio da técnica de análise de conteúdo do tipo categorial (BARDIN, 2008/1977). Foi feito uso da técnica de "história de vida" nas entrevistas realizadas. Thompson, Pollio e Locander (1994), mostram que tanto a interpretação dos significados pessoais quanto a compreensão reflexiva do eu dependem da história pessoal do consumidor.

O Quadro 1, que segue, apresenta o perfil dos entrevistados e trechos das entrevistas.

Quadro 1 - Perfil dos Entrevistados

\begin{tabular}{|c|c|c|c|c|}
\hline Entrevistado & Idade & Sexo & Porque usa? & Quando usa \\
\hline $\begin{array}{l}\text { Entrevistada } \\
\text { A }\end{array}$ & $\begin{array}{l}21 \\
\text { anos }\end{array}$ & $\mathrm{F}$ & $\begin{array}{l}\text { Proteção. "[...] dá uma blindada } \\
\text { né, contra mal olhado [..]." }\end{array}$ & "Todo dia." \\
\hline $\begin{array}{l}\text { Entrevistada } \\
\text { B }\end{array}$ & 29 & $\mathrm{~F}$ & "Proteção." & "Todo dia." \\
\hline $\begin{array}{l}\text { Entrevistada } \\
\text { C }\end{array}$ & $\begin{array}{l}37 \\
\text { anos }\end{array}$ & $\mathrm{F}$ & "Armadura de Deus." & $\begin{array}{c}\text { "Uso quando sinto a necessidade de } \\
\text { proteção." }\end{array}$ \\
\hline $\begin{array}{l}\text { Entrevistada } \\
\text { D }\end{array}$ & $\begin{array}{l}35 \\
\text { anos }\end{array}$ & $\mathrm{F}$ & $\begin{array}{c}\text { "[...] eu acredito que me } \\
\text { proteja." }\end{array}$ & "Sempre uso, direto, não tiro." \\
\hline $\begin{array}{l}\text { Entrevistada } \\
\text { E }\end{array}$ & 63 & $\mathrm{~F}$ & $\begin{array}{c}\text { "[...] me sinto forte, protegida } \\
\text { em oração." }\end{array}$ & "Uso todos os dias, não tiro." \\
\hline $\begin{array}{l}\text { Entrevistada } \\
\text { F }\end{array}$ & $\begin{array}{l}70 \\
\text { anos }\end{array}$ & $\mathrm{F}$ & "Proteção divina." & "Não tiro, nunca." \\
\hline $\begin{array}{l}\text { Entrevistado } \\
\text { G }\end{array}$ & $\begin{array}{l}61 \\
\text { anos }\end{array}$ & $\mathrm{M}$ & $\begin{array}{c}\text { "No sentido de proteção, } \\
\text { acredito que guarda de possíveis } \\
\text { males". }\end{array}$ & "Uso todo dia, não tiro." \\
\hline
\end{tabular}




\begin{tabular}{|c|c|c|c|c|}
\hline $\begin{array}{l}\text { Entrevistada } \\
\text { H }\end{array}$ & $\begin{array}{l}22 \\
\text { anos }\end{array}$ & $\mathrm{F}$ & $\begin{array}{l}\text { "Uso como forma de proteção, } \\
\text { retrata ser uma questão de fé, de } \\
\text { crença." }\end{array}$ & $\begin{array}{l}\text { "[...]quando eu vou sair de casa eu tenho } \\
\text { algum desafio eu pego ele e coloco." }\end{array}$ \\
\hline $\begin{array}{l}\text { Entrevistada } \\
\text { I }\end{array}$ & $\begin{array}{l}45 \\
\text { anos }\end{array}$ & $\mathrm{F}$ & $\begin{array}{c}\text { Conforme "[...] ele te dá } \\
\text { livramentos de acidente, de } \\
\text { assalto, de incêndio, é a } \\
\text { sensação, é a fé, para a proteção } \\
{[\ldots] \text { ". }}\end{array}$ & "Uso desde muito pequena usa, não tiro." \\
\hline $\begin{array}{l}\text { Entrevistada } \\
\text { J }\end{array}$ & $\begin{array}{l}35 \\
\text { anos }\end{array}$ & $\mathrm{F}$ & $\begin{array}{c}\text { "[...] é proteção, eu me sinto } \\
\text { tranquila com ele." }\end{array}$ & $\begin{array}{l}\text { "A todo o momento, se não está no } \\
\text { pescoço está na minha bolsa" }\end{array}$ \\
\hline $\begin{array}{l}\text { Entrevistado } \\
\text { K }\end{array}$ & $\begin{array}{l}28 \\
\text { anos }\end{array}$ & $\mathrm{M}$ & $\begin{array}{c}\text { "[...] eu me sinto protegido com } \\
\text { ele" }\end{array}$ & Eescapulário está comigo sempre." \\
\hline $\begin{array}{l}\text { Entrevistada } \\
\text { L }\end{array}$ & $\begin{array}{l}20 \\
\text { anos }\end{array}$ & $\mathrm{F}$ & $\begin{array}{l}\text { “[...]ele está guardado e para } \\
\text { mim, como ele é meu, me foi } \\
\text { dado, então ele me protege esteja } \\
\text { onde estiver, mas sempre está } \\
\text { em meus pertences" }\end{array}$ & "Fica guardado, sempre comigo." \\
\hline $\begin{array}{l}\text { Entrevistada } \\
\text { M }\end{array}$ & $\begin{array}{l}19 \\
\text { anos }\end{array}$ & $\mathrm{F}$ & $\begin{array}{l}\text { "É o sentimento de ter proteção } \\
\text { mesmo eu não usando no } \\
\text { pescoço." }\end{array}$ & "Carrego dentro da bolsa, sempre." \\
\hline $\begin{array}{l}\text { Entrevistada } \\
\mathbf{N}\end{array}$ & $\begin{array}{l}19 \\
\text { anos }\end{array}$ & $\mathrm{F}$ & "Proteção." & "Uso mais nas ocasiões religiosas." \\
\hline $\begin{array}{l}\text { Entrevistado } \\
\text { O }\end{array}$ & $\begin{array}{l}23 \\
\text { anos }\end{array}$ & $\mathrm{M}$ & "Proteção." & "Uso todos os dias, não saio sem." \\
\hline
\end{tabular}

Fonte: Elaborada pelas autoras em 11/2016

\section{Análise dos dados}

De forma unânime os entrevistados descreveram que o uso do escapulário se dá pela crença e pela fé. Baudrillard (2006) fala que a construção do significado pode acontecer com qualquer objeto desde que este demonstre uma história e que a ele seja atribuída uma relação abstrata. Neste contexto, confirmou-se o que Sciandini (2003), Scaraboto e Figueiredo (2015) pontuam de que os significados atrelados aos objetos relacionados à Igreja Católica se dão por meio da fé.

O escapulário foi considerado uma posse especial à qual os indivíduos atribuem um poder sobrenatural, como pode ser visto a seguir em alguns trechos das entrevistas em resposta à pergunta "O que o escapulário significa para você?: 
O significado do escapulário para mim, é proteção, me sinto protegida quando uso. (Entrevistada A, mulher, 21 anos).

Principalmente a proteção, é assim, nós católicos temos uma ligação com símbolos, imagens enfim. Quando uso o escapulário, sinto Jesus mais próximo de mim. (Entrevistada B, mulher, 29 anos).

Armadura de Deus, é um escudo para mim. Nenhum pensamento negativo entrará, vai bater e voltar. É assim que sinto no meu coração. E assim eu repito dentro de mim. [...] ele te dá livramentos de acidente, de assalto, de incêndio, é a sensação, é a fé, eu me identifico e sempre usei, é a tradição que vem da família, dos avós. Ganhei de minha mãe quando bem pequena, principalmente para a minha proteção. (Entrevistada C, mulher, 37 anos)

O ser humano é fraco da cabeça, tem que ter coisas para que nós possamos nos apegar, e como é um objeto real, concreto, que você pega, você acredita que a presença divina está com você. E para mim é assim. (Entrevistada I, mulher, 45 anos)

Conforme as transcrições demonstram, essa relação com o objeto é socialmente construída por meio das relações compartilhadas, como por exemplo, experiências pessoais, rituais, lugares. As posses fornecem evidência física de experiências anteriores, sentimentos e relações familiares (AHUVIA, 2005; MCCRACKEN, 2007; OLIVEIRA; VIERA, 2010). Pode-se identificar assim, que a maioria dos entrevistados menciona que a prática de uso do objeto escapulário teve a influência da crença por meio dos grupos aos quais essas pessoas pertencem, pois todos, sem exceção, mencionaram a família, ou seja, essa relação de uso demonstra ser um sentimento construído sob influência familiar como pode ser visto nos trechos de entrevista a seguir:

Minha mãe deu para mim, e para minhas irmãs de presente, uso desde adolescente, isso vem da minha mãe mesmo. (Entrevistada D, mulher, 35 anos)

Uso escapulário desde sempre, minha vó era muito religiosa e eu e minha mãe... nós rezávamos em italiano, desde pequena [...]. (Entrevistada F, mulher, 70 anos) 
Ao mesmo tempo em que está clara a memória afetiva dos sentimentos em relação à mãe que protege também fica evidente e a transferência dessa proteção para o escapulário que substitui essa mãe morta no ato de proteger (como foi identificado em alguns relatos dos entrevistados) que é a função maior de quem ama para quem ama. Ahuvia (2005) e Meurer (2011) contribuem para o entendimento da sacralização desse objeto que além da força religiosa carrega a afetividade familiar, principalmente materna. É a presença da mãe terrena transferida pela mesma para a mãe celestial presente no escapulário pelo qual convivem compartilhando a função de amar e proteger.

O sentimento de pertença no grupo é reforçado pela posse. Quando questionada "qual a importância do escapulário para você?", as afirmações demonstram a importância do reconhecimento da crença do indivíduo conforme o grupo ao qual pertence, identificando, assim, que o uso do objeto religioso expressa pertencimento a um determinado grupo do qual, a maioria dos entrevistados demonstrou sofrer influência expressiva nas escolhas de consumo. Os trechos de entrevistas a seguir deixam nítido esse fato:

Esse escapulário é importante para mim, porque minhas amigas me deram... foram duas, é legal que elas perceberam o quanto a religião é importante para mim. (Entrevistada A, mulher, 21 anos)

Esse escapulário é importante para mim porque ganhei do pessoal que eu trabalho, e eu me sinto muito bem com ele. (Entrevistado G, homem 61 anos)

Quando eu vejo alguém com um escapulário, eu penso: É uma pessoa do bem por mais que este julgamento não seja real, mas isto é muito engraçado... até a corrente de Nossa Senhora às vezes... eu olho-me... dá uma sensação... eu me identifico com esta pessoa de alguma forma... eu acho isto legal. (Entrevistada I, mulher, 45 anos)

Eu me sinto protegido com ele e quando eu tiro eu sinto que está faltando alguma coisa, ele faz parte de mim. (Entrevistado K, homem, 28 anos)

A minha mãe comenta que é bom usar o escapulário, pois ela tem conhecidos que por estarem usando o escapulário já tiveram livramentos de algumas situações perigosas, e eu sinto falta do 
escapulário, quando eu deixo em algum lugar eu fico preocupada, mas ele está sempre comigo. (Entrevistada J, mulher, 35 anos)

Quando não uso (falando sobre o escapulário), por exemplo, às vezes eu tiro para tomar banho, ou quando vou ao clube, eu sinto falta de não usar... desprotegido mesmo. (Entrevistado O, homem, 23 anos)

Esses trechos das entrevistas dialogam diretamente com Belk (2013) por colocarem o escapulário como um instrumento de experimentação do sagrado e suas propriedades mágicas estão relacionadas pelos entrevistados com o amor envolvido no ato de presentear.

\section{Considerações Finais}

Foi identificado que o Escapulário tem poder de ação social junto aos católicos sendo esse considerado uma posse especial à qual os indivíduos atribuem poder sobrenatural de proteção. Esse significado de proteção é transmitido ao objeto Escapulário pela sacralização que ocorre não apenas pela crença na religião e sim pelo ato de presentear. Todos os entrevistados relataram ter ganho o Escapulário de algum ente próximo (mãe, avó, entre outros) que no ato de presentear verbalizam do seu desejo de saber que essa pessoa passaria a estar protegida pelo objeto e, portanto, recomenda a sua utilização diária. A partir deste ritual (ato de presentear) é que o objeto passou a ser percebido pelo presenteado como sagrado e imbuído do significado de proteção. Os entrevistados demonstraram claramente memória afetiva e transferência dos sentimentos da "mãe que protege" para o escapulário que substitui essa mãe no ato de proteger que é a função maior de quem ama para quem é amado. Ahuvia (2005) contribui para o entendimento dessa sacralização que além da força religiosa carrega a afetividade familiar. Dito isso, o objeto demonstra ser a presença da mãe terrena transferida pela mesma para a mãe celestial presente no escapulário. O escapulário é objeto de amor socialmente construído por meio das relações compartilhadas como experiências pessoais, rituais, lugares. A posse do escapulário fornece a evidência física de experiências anteriores, sentimentos e relações familiares como descreve AHUVIA (2005) em relação a objetos em geral.

Em posse do Escapulário, diversas pessoas afirmaram se sentirem capacitadas a realizar atos antes julgados como impossíveis e atribuírem essa força às pessoas de quem receberam o objeto. O Escapulário é importante para que o indivíduo se identifique dentro de um grupo, para 
que externalize sua crença, para que se sinta protegido e com os poderes necessários para realizar atos que sem o mesmo não se sentiria capaz de realizar.

O presente estudo contribui com o entendimento de que o ato de presentear além de sacralizar o bem de consumo profano (BELK; WALLENDORF; SHERRY; 1989) também sacraliza o sagrado quando conjugado com o amor do presenteador para o presenteado. Concluiu-se que os três elementos que compõem o processo de sacralização do objeto escapulário são: a religião, o ato de presentear e o amor do presenteador.

O estudo apresenta contribuição teórica ao conceito de sacralização no consumo de um objeto religioso quando desvenda que o ato de presentear, o presenteador e o amor reconhecido pelo presenteado, e não apenas a crença na religião, é o que sacraliza o objeto. A intenção da pessoa que presenteia é que o transforma em objeto amado e sagrado por dupla significação de proteção: religião e amor. Porque quem ama protege... e quem não quer se sentir amado?

\title{
GIFT-GIVING AS A SCRALIZATION PROCESS: THE CATHOLIC SCAPULAR AS A SYMBOL OF LOVE AND PROTECTION
}

\begin{abstract}
In order to understand how the process of sacralization of the scapular consumption object takes place for Catholics who use this item, a qualitative investigation was carried out. Interviews were conducted with Catholics who use scapular regularly. The speeches collected went through the content analysis of the speeches of these users, which revealed, as a result of research, that the place of the "sacred" in relation to the scapular, is linked to its ability to protect its user. Yet this protective capacity is not only linked to the object itself, but to the fact that it was received as a gift by a beloved person. What sacralizes it, then, is not just religion, but the affectionate relationship between the person who received the scapular as a gift and the person who gives it.
\end{abstract}

Key words: Sacralization; Gift-giving; Loved objects.

\section{REFERÊNCIAS}

AHUVIA, Aaron C. Beyond the extended self: Loved objects and consumers' identity narratives. Journal of consumer research, v. 32, n. 1, p. 171-184, 2005.

ARAUJO, Fábio Francisco de; VIEIRA, Fabrício Correia; TURANO, Lucas Martins Subculturas Religiosas de Consumo: Um Estudo Etnográfico sobre Práticas de Consumo de Jovens Católicos. SemeAd, Curitiba, Paraná, Brasil, XVI, 2013.

BARDIN, Laurence. Análise de conteúdo. Lisboa: Edições 70; 1977. Correspondência: Daiane Dal Pai Rua Santana. 2008.

BAUDRILLARD, Jean. O sistema dos objetos. São Paulo: Perspectiva. 2006. 
BELK, Russel. W. Possessions and the extended self. Journal of consumer research, v. 15, n. 2, p. 139-168, 1988.

BELK, Russel. W.; Wallendorf, Melanie.; Sherry, John. F. The sacred and the profane in consumer behavior: Theodicy on the odyssey. Journal of consumer research, v. 16, n. 1, p. $1-38,1989$.

BELK, Russell W. The sacred in consumer culture. Consumption and spirituality, v. 16, p. 69, 2013.

BRITTO. Larissa Ruiz Golemba. A SACRALIZAÇÃO DOS PRESENTES POR MEIO DO ATO DE PRESENTEAR. Dissertação de Mestrado. PPA- Programa de Pós-Graduação em Administração. Universidade Estadual de Maringá. Maringá - Paraná, Brasil, 2019.

CENSO, Instituto Brasileiro de Geografia e Estatística. Censo 2010. Disponível em:< http://www. censo2010. ibge. gov. br/>. Acesso em, 11/01/2019, 2010.

COŞGEL, Metin. M.; MINKLER, Lanse. Religious identity and consumption. Review of Social Economy, v. 62, n. 3, p.339-350, 2004.

DIAS, Júlio César Tavares; DE SOUZA, José Roberto; DA SILVA, Drance Elias. Notas em torno dos objetos de devoção popular no Brasil. Religare, João Pessoa, v. 11, n. 2, p. 343 $355,2014$.

DOUGLAS, Mary; ISHERWOOD, Baron. D., P. O mundo dos bens: para uma antropologia do consumo. UFRJ. 2006.

HUSS, Boas. Spirituality: The emergence of a new cultural category and its challenge to the religious and the secular. Journal of Contemporary Religion, v. 29, n. 1, p. 47-60, 2014.

MAUSS, Marcel. Ensaio sobre a dádiva: forma e razão da troca nas sociedades arcaicas [1925]. Sociología e antropología, v. 2, 2003.

MCCRACKEN, Grant. Cultura e consumo: uma explicação teórica da estrutura e do movimento do significado cultural dos bens de consumo. Revista de Administração de Empresas, v.47, n. 1, p. 99-115, 2007.

MEURER, Heli. Redesenho de um escapulário. Tese de Doutorado. Laureate International Universities, São Paulo, São Paulo, Brasil, 2011.

MILLER, Daniel. Consumo como cultura material. Horizontes antropológicos, v. 13, n. 28, p. 33-63, 2007.

OLIVEIRA, Josiane Silva de; VIEIRA, Francisco Giovanni David. Com os pés na igreja e as mãos nas compras: compreendendo a influência religiosa na constituição dos significados atribuídos ao consumo de presentes de natal por jovens cristãos. Anais do Encontro de Marketing da ANPAD, 2010.

OLIVEIRA, Barbara. O bilionário mercado religioso: feiras, romarias, turismo, shows e comércio de livros, discos, imagens, móveis e acessórios são o paraíso dos empreendedores. 
FecomércioSP, 2015. Disponível em: https://www.fecomercio.com.br/noticia/mercadoreligioso-cresce-e-se-mostra-bilionario. Acesso em 21 de janeiro de 2021.

PADRE LUIZINHO. Canção Nova "Qual o verdadeiro significado do escapulário?" Disponível em: http://formacao.cancaonova.com/nossa-senhora/devocao-nossa-senhora/qualo-verdadeiro-significado-do-escapulario/ . Acesso em 15 de junho de 2020.

PARK, Joseph. Z.; BAKER, Jerry. What would Jesus by: American consumption of religious and spiritual material goods. Journal for Scientific Study of Religion, v. 46, n. 4, p. 501517, 2007.

PÉPECE, Olga Maria Coutinho. O comportamento de presentear: uma análise exploratória. Dissertação de Mestrado -Centro de Pesquisa e Pós-Graduação em Administração, Universidade Federal do Paraná, Curitiba, Paraná, Brasil, 2000.

RINALLO, Diego; SCOTT, Linda; MACLARAN, Pauline. Introduction: Unravelling complexities at the commercial/spiritual interface. In: Consumption and spirituality. Routledge, p. 17-42, 2012.

SCARABOTO, Daiane; FIGUEIREDO, Bernardo. How to Create Value via Object Circulation in Gift-Systems. In: Ethnographic Praxis in Industry Conference Proceedings, p. 235-253, 2015.

SCIADINL, Patricio. Escapulário de Nossa Senhora do Carmo. Edições Loyola, 2003.

TAJFEL, Henri. Individuals and groups in social psychology. British Journal of Social and Clinical Psychology, v.18, n.2, p.183-190, 1979.

THOMPSON, Craig J.; Pollio, Howard R.; Locander William B. The spoken and the unspoken: a hermeneutic approach to understanding the cultural view- points that underlie consumers' expressed meanings. Journal of Consumer Research, v .21, n. 3, p. 432-452, 1994.

Data de recebimento: 03/11/2019

Data de aceite: $12 / 12 / 2020$

\section{Sobre as autoras:}

Larissa Ruiz Golemba de Britto é Mestre em Administração pelo Programa de Pós-graduação Mestrado e Doutorado-PPA da UEM e membro do GIPEM (Grupo Interdisciplinar de Pesquisas e Estudos em Marketing). Endereço Eletrônico: larissargbritto@gmail.com

Olga Maria Coutinho Pépece é Professora associada da Universidade Estadual de Maringá e coordenadora do Programa de Pós-graduação Mestrado e Doutorado-PPA da UEM. É membro do Grupo de Pesquisa G-como (Grupo de Estudos em Consumo de Moda) e do GIPEM (Grupo Interdisciplinar de Pesquisas e Estudos em Marketing). Endereço Eletrônico: opepece@gmail.com

Ana Paula Celso de Miranda é Professora associada da Universidade Federal de Pernambuco e coordenadora do Grupo de Pesquisa G-como (Grupo de Estudos em Consumo de Moda). Fez 
pós-doutorado na COPPEAD-UFRJ. Autora do livro Consumo de Moda: a relação pessoaobjeto e co-autora do livro Consumo de Ativismo. Endereço Eletrônico: apcm7 @ hotmail.com

Elisabete Camilo é Mestre em Administração pelo Programa de Pós-graduação Mestrado e Doutorado-PPA da UEM e professora colaboradora do Departamento de Administração da Universidade Estadual de Maringá. Endereço Eletrônico: bcamilo@uol.com.br 